\title{
Preparing Teachers for Emotional Labour: The Missing Piece in Teacher Education
}

\author{
Tonje M. Molyneux \\ The University of British Columbia
}

\begin{abstract}
A quality education for all children and youth is required for the continued advancement of modern civilization. But this outcome is threatened by a growing international teacher shortage. Increased rates of teacher attrition and reduced rates of enrollment in teacher education programs are driving this shortage; however, research suggests that teacher candidates' lack of preparation for the emotional labour of teaching is another important contributing factor, one which can be addressed in teacher education programs. The aim of this paper is to explore this problem and surface potential solutions. First, the social historical context of teaching is explored as an entry point to inquiry into this topic. Next, through discussion of the emotional nature of teaching, the thesis that teacher candidates must be prepared to handle the emotional labour of teaching during their teacher education program is advanced. Then, a review of the literature surfaces three key content areas which if addressed during teacher preparation can help prepare teacher candidates to handle the emotional labour of teaching: identity development, emotions and teaching, and social-emotional competence. Finally, these components are included in a theory of change for a new program that could be integrated into existing teacher education programs.
\end{abstract}

\section{The Missing Piece in Teacher Preparation}

Around the world, teachers are leaving the profession in droves (Garcia \& Weiss, 2019; McDonald, 2019; Moon, 2007; Sutcher et al., 2016; Walker, 2019). Worse yet, fewer people are choosing to enter the profession at all (The Association of Universities and Colleges of Canada, 2011; Partelow, 2019). For example, in the United States (US) the number of students enrolling in teacher preparation programs dropped by one third between 2010 and 2018 (National Center for Education Statistics, 2019). This teacher shortage threatens the bedrock of our collective potential to advance as a civilization: a quality education for children and youth. Well-trained, qualified 
teachers are key for ensuring students get the education that will prepare them to participate fully and positively in both local and global contexts (Darling-Hammond, 1999). Typical teacher preparation programs focus on the content and pedagogical knowledge required to teach (DarlingHammond, 2006), but this approach is missing a critical piece. As with the growing movement in education to educate the whole child, teacher preparation programs must seek to educate the whole person. They must take into account the human condition and the wholeness of human experience evident in a helping profession like teaching, one which demands that teachers exert extensive mental, physical, and emotional energy to build and sustain positive relationships with students and their families, and with their colleagues; and to design and deliver engaging, relevant learning experiences aligned with state educational standards to groups of learners with varying abilities, needs, and backgrounds.

In what follows, I argue that in order to prepare teachers for the emotional labour teaching entails, teacher preparation programs must broaden their focus to include opportunities for teacher candidates to formulate a teacher identity, to understand how emotions affect teachers and teaching, and to develop social-emotional competencies that will help them face the rigours of teaching with resilience. As an entry point into this topic, the first section of this paper describes the social historical context of teaching; specifically, the nature of the teacher shortage, its causes, and the emotional work of teaching are reviewed. This is followed by a review of the literature that points to content in three areas that can improve teacher candidates' ability to handle the emotional labour of teaching: identity development, emotions and teaching, and social-emotional competence. Key implications for teacher preparation programs are offered for each area. Finally, the theory of change for a new program aimed at preparing teacher candidates for the emotional labour of teaching is presented.

\section{Social Historical Context of Teaching}

An examination of the social historical context of teaching brings into focus the urgent need to change how we prepare teachers. Schutz (2014) argues that situating one's research process within its social historical context is a more realistic approach given that it is from within these contexts that problems develop, and solutions should be tested. Additionally, it is important to acknowledge the many levels nested within the social historical context and that transactions between and within these layers also bear investigation. However, a comprehensive examination of all aspects is beyond the scope of this paper. The following considers one emergent issue in the social historical context of the teaching profession today - the teacher shortage — and its causes including high rates of teacher attrition and reduced rates of enrollment in teacher preparation programs. Then, through discussion of the emotional nature of teaching, the central thesis that teacher preparation programs need to expand their focus to prepare teacher candidates for the emotional labour of teaching is introduced.

\section{Teacher shortage: A worsening crisis}

Recent reports and articles have called attention to a teacher shortage that seems to be getting worse (Garcia \& Weiss, 2019; McDonald, 2019; Moon, 2007; Sutcher et al., 2016; Walker, 2019). In their seminal report, Sutcher et al. (2016) projected the gap between teacher supply and demand in the US to rise to 100,000 public school teacher vacancies by the year 2025. Less is known about teacher supply and demand in Canada (Kareseti \& Collin, 2013), but provinces like 
British Columbia and Ontario have recently needed to scramble to keep up with the sharp increases in demand prompting efforts to compile a national dataset to help governments and faculties of education curtail the growing teacher shortage (McDonald, 2019). A United Nations Educational, Scientific, and Cultural Organization (UNESCO) report examined teacher shortages in Europe, Sub-Saharan Africa, South and West Asia, and the US and found evidence of rising shortages in each region (Moon, 2007). More recently, the UNESCO Institute for Statistics estimated that the world would need to recruit 68.8 million teachers in order to reach its goal of "Education for all" which aims to provide every child with equal access to a quality education and lifelong learning opportunities (UNESCO Institute for Statistics, 2016). This staggering figure highlights the urgency to address this crisis because without an adequate supply of qualified teachers, students' ability to learn is jeopardized (Darling-Hammond, 1999). And without a quality education, students will not be prepared to join the workforce or contribute to society in other ways. Understanding the factors driving the teacher shortage is an important first step. Therefore, the following exposes two factors reported to be causing the teacher shortage: increased teacher attrition and reduced enrollment in teacher preparation programs.

Rising teacher attrition. The factor contributing to the teacher shortage cited most widely in the literature is teachers leaving the profession early in their careers (e.g., Chang, 2009; Gallant \& Riley, 2014; Schutz, 2014; Sutcher et al., 2016). In fact, Sutcher et al. (2016) assert: "changing attrition would change the projected shortages more than any other single factor," (p. 2). While attrition rates vary, the general rate reported in most countries is a loss of about $40-50 \%$ of teachers in the first five years of their career. The causes of early leaving are myriad and vary by area and subpopulation (Sutcher et al., 2016) which highlights how the socio-ecological context influences this issue. There is consensus that the following factors contribute to teachers' decision to leave the profession: working conditions (e.g., lack of administrator support, lack of autonomy, negative school culture); excessive stress (burnout, emotional exhaustion), poor teacher preparation, and low wages (Borman \& Dowling, 2008; Chang, 2009; Grimmett \& Echols, 2000; Karsenti \& Collin, 2013; Kyriacou, 2001; Maslach, 1999; Sutcher et al., 2016).

Another issue affecting teacher supply and demand is concurrent increases in student enrolment and teacher retirements when the profession's low wages and other issues make it a less appealing career choice (Grimmett \& Echols, 2000). For example, in the early 2000s Ontario projected a massive teacher shortage due to the anticipated retirements of an aging workforce; however, this was partially averted due to delayed retirements prompted by the 2008-09 economic crisis (Sweeney, 2011). Ontario has had some success building its teaching workforce over the last decade, despite especially first-generation Canadians choosing higher-paying career paths (Sweeney, 2011). However, when put to the test recently with demands brought on by the coronavirus epidemic, an inadequate teaching supply was revealed. The Ontario College of Teachers recently had to issue a call to retired and non-practising teachers to return to the classroom to meet the demand (Rushowy, 2020). Another example of the precarious nature of teacher supply and demand is found in British Columbia (BC) where maintaining an adequate teaching supply has been an ongoing problem for decades (Uguen-Csenge, 2019). In addition to projected increases in retirement, Grimmett and Echols (2000) also cite curriculum change, adversarialism, and managerialism as factors contributing to BC teachers leaving the profession, or to others choosing not to join the profession at all.

Reduced enrollment in teacher preparation programs. Alongside people leaving the profession of teaching, that fewer are choosing to pursue this career is another significant contributor to the teacher shortage. A recent report from the Center for American Progress found that enrollment in teacher preparation programs in the US decreased by a third from 2010 to 2018 
(Partelow, 2019). The Association of Universities and Colleges of Canada (AUCC; 2011) reports a similar trend in Canada noting a 50\% decrease in students enrolling in part-time undergraduate studies in education between 1992 and 2007. Among those who do enter teacher preparation programs, far fewer are completing them (Partelow, 2019). Troublingly, this same period of decreased enrollment in teacher preparation programs in institutions of higher education has also been marked by increased enrollment in alternative routes to teacher certification (Partelow, 2019). These programs provide truncated training to ensure swift certification, but the result is poorly prepared teachers who are more likely to leave the profession in their first few years (DarlingHammond, 2006).

Given current public perception of the teaching profession this downward trend in teacher preparation program enrollment will likely continue. In a recent survey in the US, 54\% of respondents indicated they would not want their children to pursue a career in teaching (Langer Research Associates, 2019). Similarly, in a survey administered in the UK, only 50\% of respondents viewed teaching as an attractive career, and young people responded negatively more often than older people (Everton et al., 2007). Contributing to this public perception is the changing nature of teacher professionalism. In an age of educational reform, teachers are being held accountable for students' performance on high-stakes tests while simultaneously being limited in their ability to exercise their educational expertise (Osmond-Johnson, 2018). Indeed, when asked to give reasons for viewing teaching negatively, UK survey respondents cited lack of authority in addition to pay, workload, and status (Everton et al., 2007). Aside from the factors reviewed thus far, what else about the nature of teaching or the teaching environment makes it a difficult profession to stay in or an undesirable one to even enter? Gallant and Riley (2014) suggest investigating factors related to the human condition such as teachers' identity and emotional experience to answer this question.

\section{The emotional nature of teaching}

In his collection of essays on teaching, learning, and learning to teach, Schulman (2004) writes, "After some 30 years of doing such work, I have concluded that classroom teaching...is perhaps the most complex, most challenging, and most demanding, subtle, nuanced and frightening activity that our species ever invented," (p. 504). Indeed, research shows that teaching is one of the most stressful occupations there is even surpassing stress levels found in the nursing profession (Greenberg, Brown, \& Abenavoli, 2016). Periods of prolonged stress can lead to burnout (Maslach et al., 2001), cited above as a factor contributing to teacher attrition, and teaching is a profession known for this phenomenon (Chang, 2009). Maslach et al. (2001), who with other colleagues created a scale to measure teacher burnout, classify emotional exhaustion as the "central quality of burnout and the most obvious manifestation of this complex syndrome," (p. 402). Therefore, the role of emotions in teaching and teachers presents as an area warranting investigation.

The emotional nature of teaching has garnered some attention in the literature (e.g., Schutz \& Zembylas, 2009). In a complex interplay with thoughts and decisions, emotions drive behavior and social functioning (Immordino-Yang \& Damasio, 2007). How we feel affects what and how well we learn, making emotions both an inevitable and important part of learning (ImmordinoYang et al., 2018; Zembylas, 2005). Schutz and colleagues (2009) provide insight into the role the teacher plays in this emotional learning process: 
In essence, schooling, in whatever forms it takes, at its core involves processes of enculturalization where what is believed in and valued within and among cultures is acted and reenacted in ritualized activity settings. It is during these social historical contextualized events that teachers experience, display, and/or create affective experiences. As such affective experiences are intricately woven into the fabrics of classroom experiences." (p. 195)

These shared affective experiences reflect the relational nature of teaching, and the studentteacher relationship is built on a foundation of caring in which the teacher is the carer and the students are cared for (Noddings, 1992; 2012). Caring and its association with good teaching is recognized in the literature (Collinson et al., 1999; Noddings, 1992; 2012), but fostering and nurturing the caring relationship requires that teachers perform emotional labour (Isenbarger \& Zembylas, 2006). Emotional labour is understood as the effort teachers must employ to control their emotion display and to regulate emotions that may compromise their teaching goals (Schutz, 2014). Isenbarger and Zembylas (2006) locate it in the caring relationship teaching entails: "[E]motional labour is what teachers perform when they engage in caring relationships but they have to induce, neutralize or inhibit their emotions so as to render them appropriate to situations," (p. 123).

The costs of teachers' emotional labour can be great, especially for beginning teachers (Gallant \& Riley, 2014; Nichols et al., 2017; Phillip \& Schüpbach, 2010). The intense emotional control emotional labour entails can affect teachers' well-being and lead to increased stress and burnout (Grandey \& Gabriel, 2015; Hülsheger \& Schewe, 2011; Isenbarger \& Zembylas, 2006). Some researchers have suggested that emotional labour explains why so many teachers are fleeing the profession (Schutz \& Zembylas, 2006). Early career teachers are particularly vulnerable to the harmful effects of the emotional labour of teaching because they are rarely prepared for it (Bahia et al., 2013) and are still forming their teacher identities (Nichols et al., 2017). That teachers are not prepared to handle the emotional labour of teaching during their vulnerable first years points to a clear need to address this in teacher education programs.

Teachers perform emotional labour is a variety of ways. Emotional labour strategies include surface acting (e.g., hiding or faking emotions), deep acting (e.g., reappraising emotions), and genuine expression (Grandey \& Gabriel, 2015). Importantly, only surface acting has been positively associated with job burnout (Hülsheger \& Schewe, 2011). For example, in a recent study with PE teachers, Lee (2019) found surface acting to be positively associated with all aspects of teacher burnout. Interestingly, when exploring the relation between emotional labour strategies, teacher enthusiasm, and class outcomes (e.g., intrinsic motivation, positive affect, deep learning strategy), Burić (2019) divided surface acting into two strategies - faking feelings and hiding feelings - and found that only hiding feelings was negatively correlated with teacher enthusiasm and class positive affect. Taken together, these findings suggest that teacher candidates may benefit from explicit instruction in the nature of emotional labour and its strategies to develop their selfawareness and prepare them to cope effectively in the classroom

\section{Implications for Teacher Education}

There is a mass exodus from teaching underway, and fewer people choosing it as a career path. Instead of simply lamenting this sad state of affairs, teacher educators and teacher education programs need to take swift and decisive measures to change how teacher candidates are prepared. Sufficient inoculation against the potentially harmful effects of the emotional labour of teaching 
could help prevent the burnout that is driving teachers from their classrooms. A review of the literature reveals three key content areas that may help prepare teacher candidates to deal with the emotional labour of teaching: 1) teacher identity; 2) emotions and teaching; and 3) socialemotional competence. Each of these content areas is addressed in more detail below.

\section{Developing teacher candidates' teacher identity}

Teacher candidates begin their teacher education program with educational beliefs based on their prior experiences in school (Pajares, 1992), but their teacher identity is still emerging which can lead to greater emotional labour when their incoming beliefs are questioned during early classroom experiences (Nichols et al., 2017; Zhu, 2017). For example, if they experience strong, negative emotions in early classroom encounters, this may signal a threat to their emerging identities or beliefs about teaching whereas more positive emotional experiences can confirm their beliefs (Nichols et al., 2017). Through interviews of seven Chinese student teachers following their practicums, Zhu (2017) identified a range of negative emotional experiences and attributed this to a lack of identity formation work prior to their student teaching experiences. Therefore, one way to potentially reduce the risk of excessive emotional labour for early career teachers is to integrate professional teacher identity development work into teacher education programs (Beauchamp \& Thomas, 2010). This can be accomplished through exploration of educational beliefs and reflection on practicum experiences.

Beliefs are defined simply as "an individual's judgment of the truth or falsity of a proposition," (Pajares, 1992, p. 316). For teachers, they can include implicit or explicit beliefs about the self, knowledge, pedagogy, and students (Buehl \& Beck, 2015; Fives \& Buehl, 2012). Teachers' beliefs significantly influence their practice and are difficult to change (Buehl \& Beck, 2015). Fives and Buehl (2012) identify three functions of teachers' beliefs: 1) filters for interpreting experiences and content; 2) frames to conceptualize or define a problem or task; and, 3) guides for action. The filtering function of preservice teachers' beliefs is salient to the development of their professional teacher identity as they integrate the new knowledge and experiences encountered in preservice education into their emerging identity (Fives \& Buehl, 2012). Teacher identity can also include goals, standards, and how teachers perceive themselves (Schutz et al., 2007). Schutz et al. (2009) recommend incorporating two activities into teacher preparation to aid in identity formation: 1) writing teaching philosophies, and, 2) engaging in reflective journaling. These activities are currently part of most teacher education programs, but they can be strengthened with explicit instruction regarding the function of education beliefs and their influence on teaching (Fairbanks et al., 2010). Then when composing their teaching philosophies, teacher candidates can identify educational beliefs that are congruent with their emerging teacher identity. Reflective journaling throughout their program, in particular in conjunction with practicum experiences, can help teacher candidates refine their beliefs as they incorporate new knowledge and understandings gained during their program. Further, teacher candidates can develop the practice of continually revisiting their educational beliefs as they shift and evolve throughout their career. Figure 1 depicts how these activities can be accomplished in, for example, a year-long post-baccalaureate teacher education program by inserting them at different points before, during, and after teacher candidates' practicum experiences. 


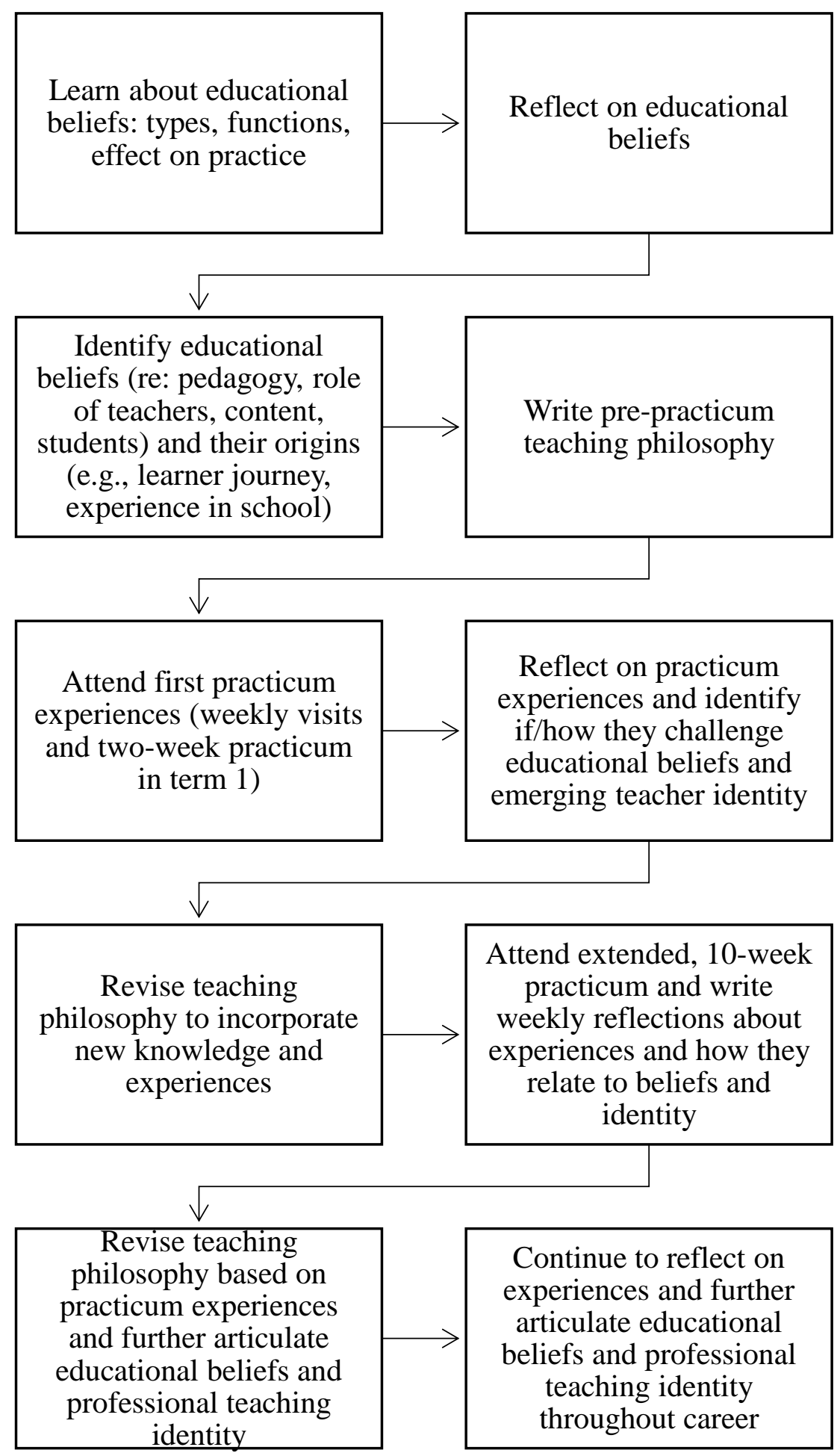

Figure 1: Teaching identity development process implemented in one-year post-baccalaureate teacher education program. 


\section{Increasing teacher candidates' understanding of emotions and teaching}

As demonstrated above, teachers' beliefs inform how they identify as teachers which in turn influences their practice. Emotions also play a role in these transactions perhaps carrying even more weight in how they influence teaching and learning (Gill \& Hardin, 2015; Schutz et al., 2009). However, most teachers report feeling unprepared to create and maintain a positive emotional climate in their classroom (Bahia et al., 2013; Schutz et al., 2009) despite agreement among researchers of emotion in education that this responsibility lies with the teacher (Gill \& Hardin, 2015). To address this gap, several researchers argue that specific instruction regarding the emotional nature of the classroom needs to be included in teacher education programs (Chang, 2009; Fairbanks et al., 2010; Nichols et al., 2017; Schutz et al., 2006, 2009). A useful starting point for determining course content is found in Hargreaves' (1998) conceptual framework of emotions in teachers' work and professional development. Based on research in teaching and the sociology of emotions, the conceptual framework includes seven topics of inquiry into emotions and teaching as embedded in the socio-cultural context of school:

1. teaching is an emotional practice;

2. teaching and learning involve emotional understanding;

3. teaching is a form of emotional labour;

4. teachers' emotions are inseparable from their moral purposes and their ability to achieve those purposes;

5. teachers' emotions are rooted in and affect their selves, identities and relationships with others;

6. teachers' emotions are shaped by experiences of power and powerlessness;

7. teachers' emotions vary with culture and context. (p. 319, emphasis in original)

Similar to the process for exploring educational beliefs and how they shape teachers' identity, teacher candidates can explore topics related to emotions and teaching before, during, and after their practicums, thus engendering a practice of reflecting on emotions and teaching they can apply throughout their careers. Given the role of emotional labour in teacher stress and burnout, this topic warrants explicit and thorough coverage in preservice teacher education. Incorporating these lines of inquiry into teacher preparation programs can help raise teacher candidates' awareness regarding the role emotions play in teaching and help prepare them to create a positive emotional climate and handle emotional experiences in their classrooms. Figure 2 shows how these topics can be explored in, for example, a year-long post-baccalaureate teacher education program by inserting them at different points before, during, and after teacher candidates' practicum experiences. 


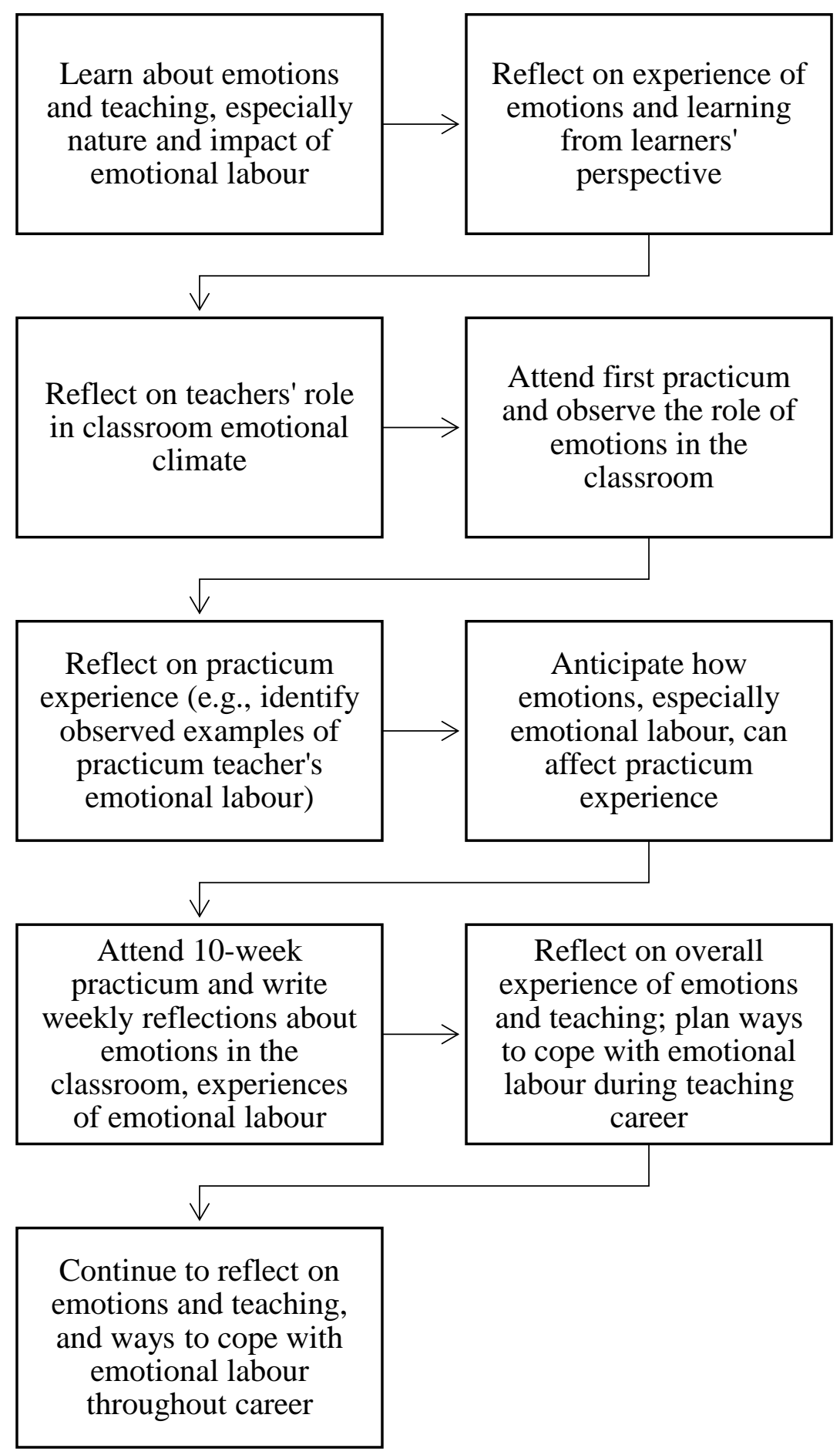

Figure 2: Emotions and teaching course content and flow in one-year post-baccalaureate teacher education program. 


\section{Building teacher candidates' social-emotional competence}

In addition to understanding the emotional nature of teaching, emotion in education researchers also assert that teacher preparation should include skill development in emotion knowledge, understanding, and regulation (Chang, 2009; Schutz et al., 2006; Zembylas \& Schutz, 2009). These skills are associated with the broader construct of social-emotional competence (SEC) which includes competencies in five areas: self-awareness, self-management, social awareness, relationship skills, and responsible decision-making (CASEL, 2019). People with high social-emotional competence can effectively recognize and manage emotions, feel and show care and concern for others, establish and maintain positive relationships, make responsible decisions, and set and achieve positive goals. In the student-focused literature, the process of developing SEC is known as social-emotional learning (SEL) (e.g., Hymel et al., 2017). SEL is described as the missing piece in education for children and youth (Civic Enterprises, Bridgeland, Bruce, \& Hariharan, 2013); however, it may also be the missing piece in teacher education, especially given the effects of the emotional labour teaching entails discussed previously. The following briefly reviews the importance of teachers' SEC then discusses two programs which could be used in teacher preparation to help teacher candidates develop it.

Importance of teachers' social-emotional competence. Teachers' social-emotional competence (SEC) as a positive force in the classroom is clearly evident in Jennings and Greenberg's (2009) Prosocial Classroom Model. Based on an extensive review of the literature, their model suggests that teachers with greater SEC experience lower rates of stress and burnout, have more positive relationships with students, and demonstrate more effective classroom management (Jennings \& Greenberg, 2009). This can yield a more positive, emotionally supportive classroom environment and improved student outcomes. Importantly, as significant emotion socializers (Garner, 2010), teachers who are better able to model social-emotional competence can also provide better support for students' social-emotional development (Garner, 2010; Schonert-Reichl et al., 2015). Moreover, given the evidence positioning SEL as key for students' healthy development and well-being (e.g., Durlak et al., 2011), having sociallyemotionally competent teachers in the classroom is clearly an asset. Although some teacher education programs do address aspects of SEL (Schonert-Reichl et al., 2017), specific attention to developing teacher candidates' SEC is missing despite its being an identified need for practicing teachers (Collie, 2017, 2019; Collie \& Perry, 2019; Jennings \& Greenberg, 2009).

Programs to develop teacher candidates' social-emotional competence. Programs targeting teachers' SEC are a relatively new phenomenon therefore few have been developed and tested (Jones et al., 2013). Fewer still have been developed and tested with teacher candidates. In fact, a search of the literature surfaced merely one such program (Beltman et al., 2018). Those that have been evaluated with teachers have demonstrated significant positive effects on teachers' wellbeing, efficacy, and stress (e.g., Jennings et al., 2013) and teacher candidates' capacity for resilience, efficacy, and coping (Beltman et al., 2018). These findings suggest that programs aimed at developing preservice and in-service teachers' SEC are fertile ground for development and research. Two such programs are briefly described below as promising candidates for developing teacher candidates' SEC.

Cultivating Awareness and Resilience in Education (CARE) is a model of teacher professional development grounded in Jennings and Greenberg's (2009) prosocial classroom theoretical model (Jennings et al., 2013). Through mindfulness-based approaches, compassion practices, and emotion skills training, the intervention targets improvement in three areas: 1) teacher well-being, efficacy, and mindfulness; 2) classroom organization, instructional support, 
and emotional support; and, 3) student academic achievement, behavior, and student/teacher relationships (Jennings et al., 2013). CARE is a 30-hour program consisting of four day-long sessions delivered over the course of 4-6 weeks with interleaving phone coaching sessions followed by a booster session taking place a couple of months later (Jennings et al., 2013). In a recent randomized controlled trial of CARE, the intervention resulted in significant improvements to teacher well-being, efficacy, stress, and mindfulness when compared with controls, and these improvements were associated with improvements in both classroom and student outcomes (Jennings et al., 2013). 87\% of the teachers participating agreed that a program like CARE should be included in teacher preparation and inservice training (Jennings et al., 2013) which alongside its positive outcomes make CARE a promising candidate for inclusion in a teacher education program.

Based on the conceptualization of resilience as a capacity, process, and outcome, the Building Resilience in Teacher Education (BRiTE) program features a collection of online modules designed to increase teacher candidates' capacity for resilience in the teaching profession (Beltman et al., 2018). Module content is organized around five themes: 1) understanding and building resilience (what it is and why it is important); 2) relationships (support networks, effective communication); 3) well-being (stress management, work-life balance); 4) emotions (emotion management, positive thinking); and, 5) motivation (self-efficacy, help-seeking) (Beltman et al., 2018), all of which are related to social-emotional competence (Collie \& Perry, 2019). Through self-paced, online activities about each of these themes, BRiTE targets the development of the personal (e.g., social-emotional competence, motivation, efficacy) and contextual resources (e.g., relationships, support networks, school culture), and resilience strategies (e.g., time management, work-life balance, problem solving) that can contribute to teacher candidates' capacity for resilience (Beltman et al., 2018). In an evaluation of the program's effectiveness, researchers found that teacher candidates who completed BRiTE modules and applied the strategies in their final practicum scored higher on measures of resilience than participants who did not report using the strategies (Beltman et al., 2018). Significant increases in teaching efficacy and coping strategies (appraisal and social) were also found (Beltman et al., 2018). The flexibility of implementation the online modules allow together with the positive outcomes make BRiTE a potentially beneficial program to integrate into teacher preparation.

\section{Preparing Teacher Candidates for Emotional Labour with the HELP Program}

Teacher education programs typically focus on imbuing teacher candidates with the content and pedagogical knowledge they need to be effective teachers (Darling-Hammond, 2006). However, given the emotional labour the job entails and its potential impact on teachers' likelihood to remain in the profession, teacher education programs must also prepare teacher candidates to cope effectively. Three promising ways to achieve this end were outlined above. In what follows, these components are presented in a theory of change, here named the Hybrid Emotional Labour Preparation (HELP) program. The theory of change also includes a summary of the targeted learning outcomes and potential proximal and distal outcomes as informed by the literature.

\section{HELP Program Theory of Change}

The Hybrid Emotional Labour Preparation (HELP) program (see Figure 3) is proposed here with an emphasis on three components that, in combination, can prepare teacher candidates to handle the emotional labour of teaching: 1) identity development work; 2) emotions and 
teaching course content; 3) SEC development. The components target increases in teacher candidates' self-awareness; emotion knowledge and understanding; knowledge about emotions and teaching; and ability to regulate difficult emotions. Improvements in these targeted areas are related to hypothesized proximal outcomes that include increased early career teacher socialemotional competence and student engagement, and more positive early career teacher-student relationships and classroom climate. The hypothesized distal outcomes include increased student academic achievement and teacher retention; improved teacher life satisfaction; and decreased rates of teacher burnout. Potential moderators of these hypothesized outcomes include level of administrator support, school culture and climate, specific teaching assignment (e.g., high-needs population), perceived teaching efficacy, and educational beliefs, all of which have been shown in the research to influence teachers' stress and job satisfaction (Jennings \& Greenberg, 2009; Kyriacou, 2001; Schonert-Reichl, 2017).

\begin{tabular}{|c|c|c|c|}
\hline 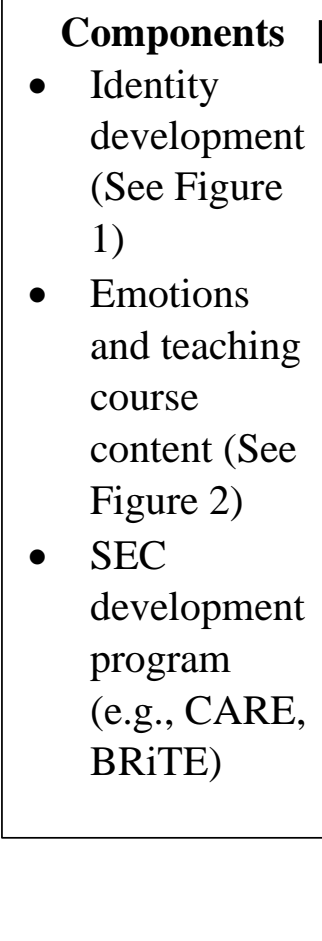 & $\begin{array}{l}\text { Targets } \\
\text { Increased self- } \\
\text { awareness (e.g., } \\
\text { teacher identify, } \\
\text { beliefs, values) } \\
\text { - Increased } \\
\text { knowledge and } \\
\text { understanding } \\
\text { of emotions, } \\
\text { and emotions in } \\
\text { the classroom } \\
\text { Increased } \\
\text { ability to } \\
\text { recognize and } \\
\text { regulate } \\
\text { difficult } \\
\text { emotions }\end{array}$ & $\begin{array}{ll}\text { Proximal } \\
\text { Outcomes } \\
\text { - } & \text { Increased } \\
\text { early career } & \text { teacher } \\
\text { social- } \\
\text { emotional } \\
\text { competence } \\
\text { More } \\
\text { positive } \\
\text { classroom } \\
\text { climate } \\
\text { Increased } \\
\text { student } \\
\text { engagement } \\
\text { More } \\
\text { positive } \\
\text { relationships }\end{array}$ & 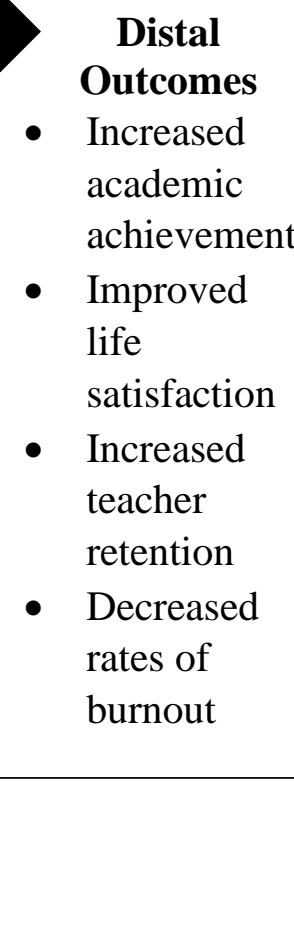 \\
\hline & & \multicolumn{2}{|c|}{$\begin{array}{l}\text { Moderators: Administrator support, } \\
\text { school culture and climate, teaching } \\
\text { assignment, perceived teaching efficacy, } \\
\text { educational beliefs }\end{array}$} \\
\hline
\end{tabular}

Figure 3: Proposed HELP theory of change 


\section{Teachers and Teaching: Towards a Brighter Future}

McDonald's (as cited in Goodwin, 2011) declaration that "teaching is in fact, the mother of all professions" (p. 44) is a compelling reason to prepare teacher candidates for all that teaching entails so they can provide their students with a quality education, thus enabling them to fulfill their potential in the profession or vocation of their choosing. However, students' ability to receive this education from well-trained professionals is at risk due to increased rates of teacher attrition, reduced enrollment in teacher preparation programs, and the resultant worldwide teacher shortage. The lack of preparation for the emotional labour of teaching is one factor contributing to these problems that can be addressed through changes to teacher education programs. This involves moving beyond content and pedagogical knowledge and educating the whole teacher candidate by providing them with the time and space to develop a teacher identity, to understand the emotional work of teaching, and to gain the social-emotional competence needed to handle the stress and challenges of teaching. The HELP program outlined above has the potential to address this gap and to create a new generation of teachers trained for both the pedagogical and emotional dimensions of teaching. Education researchers can help improve teacher preparation, reduce teacher attrition, and end the teacher shortage crisis by developing and testing programs like HELP thus creating a brighter future for all.

\section{Author Bio}

Tonje M. Molyneux, M.Ed., M.A., is an experienced educator and curriculum developer. Her recent experience includes over ten years developing programs for Committee for Children, including the Second Step social and emotional learning program. Tonje is currently pursuing further graduate studies at the University of British Columbia (UBC) in the Educational and Counselling Psychology, and Special Education Department. Her research focuses on the role of educators in supporting students' social and emotional development through the process of social and emotional learning. In addition to her studies and consulting work, Tonje is also a graduate teaching assistant and teacher candidate mentor for UBC's B.Ed. program. 


\section{References}

Bahia, S., Freire, I., Amaral, A., \& Estrela, M.T. (2013). The emotional dimension of teaching in a group of Portuguese teachers. Teachers and Teaching, 19(3), 275-292.

https://doi.org/10.1080/13540602.2012.754160

Beauchamp, C., \& Thomas, L. (2010), Reflecting on an ideal: Student teachers envision a future identity. Reflective Practice, 11(5), 631-643. https://doi.org/10.1080/14263943.2010.516975

Beltman, S., Mansfield, C.F., Wosnitza, M., Weatherby-Fell, N., \& Broadley, T. (2018). Using online modules to build capacity for teacher resilience. In M. Wosnitza, F. Peixoto, S. Beltman, \& C.F. Mansfield (Eds.), Resilience in education (pp. 237-253). Springer International Publishing. https://doi.org/10.1007/978-3-319-76690-4_14

Borman, G. D., \& Dowling, N. M. (2008). Teacher attrition and retention: A meta-analytic and narrative review of the research. Review of Educational Research, 78, 367-409. https://doi.org/10.3102/0034654308321455

Buehl, M.M., \& Beck, J.S. (2015). The relationship between teachers' beliefs and teachers' practices. In H. Fives \& M.G. Gill (Eds.), International handbook of research on teachers' beliefs (pp. 66-84). Routledge.

Burić, I. (2019). The role of emotional labor in explaining teachers' enthusiasm and students' outcomes: A multilevel mediational analysis. Learning and Individual Differences, 70, 1220. https://doir.org/10.1016/j.lindif.2019.01.002

CASEL. (2019). What is SEL? https://casel.org/what-is-sel/

Chang, M. L. (2009). An appraisal perspective of teacher burnout: Examining the emotional work of teachers. Educational Psychology Review, 21, 193-218. https://doi.org/10.1007/s10648-009-9106-y

Civic Enterprises with Peter D. Hart Research Associates, Bridgeland, J., Bruce, M., \& Hariharan, A. (2013). The missing piece: A national teacher survey on how social and emotional learning can empower children and transform schools. Collaborative for Academic, Social, and Emotional Learning. https://casel.org/wp-content/uploads/2016/ 01/the-missing-piece.pdf

Collie, R.J. (2017). Teachers' social and emotional competence: Links with social and emotional learning and positive workplace outcomes. In E. Frydenberg, A.J. Martin, \& R.J. Collie (Eds.), Social and emotional learning in Australia and the Asia-Pacific (pp. 167-184). Springer Nature. https://doi.org/10.1007/978-981-10-3394-0_0

Collie, R.J. (2019). The development of social and emotional competence at school: An integrated model. International Journal of Behavioral Development, 1-12. https://doi.org/10.1177/0165025419851864

Collie, R.J., \& Perry, N.E. (2019). Cultivating teacher thriving through social-emotional competence and its development. The Australian Educational Researcher, 46, 699-714. https://doi.org/10.1007/s13384-019-00342-2

Collinson, V., Killeavy, M., \& Stephenson, H. (1999). Exemplary teachers: Practicing an ethic of care in England, Ireland, and the United States. Journal for a Just and Caring Education, 5, 349-366.

Darling-Hammond, L. (1999). Teacher quality and student achievement: A review of state policy evidence. Center for the Study of Teaching and Policy. University of Washington. https://bit.ly/34Xc5MT

Darling-Hammond, L. (2006). Constructing $21^{\text {st }}$-century teacher education. Journal of Teacher Education, 57(3), 300-314. https://doi.org/10.1177/0022487105285962 
Durlak, J.A., Dymnicki, A.B., Taylor, R.D., Weissberg, R.P., \& Schellinger, K.B. (2011). The impact of enhancing students' social and emotional learning: A meta-analysis of schoolbased universal interventions. Child Development, 82(1), 405-432. https://bit.ly/2CZDLnS

Everton, R., Turner, P., Hargreaves, L., \& Pell, T. (2007). Public perceptions of the teaching profession. Research Papers in Education, 22(3), 247-265. https://doi.org/10.1080/02671520701497548

Fairbanks, C.M., Duffy, G.G., Faircloth, B.S., He, Y., Levin, B., Rohr, J., \& Stein, C. (2010). Beyond knowledge: Exploring why some teachers are more thoughtfully adaptive than others. Journal of Teacher Education, 61(1-2), 161-171. https://doi.org/ 10.1177/ 0022487109347874

Fives, H., \& Buehl, M.M. (2012). Spring cleaning for the "messy" construct of teachers' beliefs: What are they? Which have been examined? What can they tell us? In K.R. Harris, S. Graham, \& T. Urdan (Eds.), APA educational psychology handbook: Vol. 2. individual differences and cultural and contextual factors (pp. 471-499). American Psychological Association.

Gallant, A., \& Riley, P. (2014). Early career teacher attrition: New thoughts on an intractable problem. Teacher Development, 18(4), 562-580. https://doi.org/10.1080/ 13664530.2014 .945129

Garcia, E., \& Weiss, E. (2019). The teacher shortage is real, large and growing, and worse than we thought. Economic Policy Institute. https://bit.ly/2rhpoZG

Garner, P.W. (2010). Emotional competence and its influences on teaching and learning. Educational Psychology Review, 22(3), 297-321. https://doi.org/10.1007/ s10648-010-9129-4

Gill, M.G., \& Hardin, C. (2015). A “hot" mess: Unpacking the relation between teachers' beliefs and emotions. In H. Fives \& M.G. Gill (Eds.), International handbook of research on teachers' beliefs (pp. 230-245). Routledge.

Goodwin, A.L. (2011). Teaching as a profession: Are we there yet? In C. Day (Ed.), Routledge international handbook of teacher and school development (pp. 44-56). Routledge.

Grandey, A.A., \& Gabriel, A.S. (2015). Emotional labor at a crossroads: Where do we go from here? Annual Review of Organizational Psychology and Organizational Behavior, 2, 323349. https://doi.org/10.1146/annurev-orgpsych-032414-111400

Greenberg, M.T., Brown, J.L., \& Abenavoli, R.M. (2016). Teacher stress and health: Effects on teachers, students, and schools. Edna Bennett Pierce Prevention Research. Pennsylvania State University. https://www.rwjf.org/en/library/research/2016/07/teacher-stress-andhealth.html

Grimmett, P.P., \& Echols, F.H., (2000). Teacher and administrator shortage in changing times. Canadian Journal of Education, 25(4), 328-343.

Hargreaves, A. (1998). The emotional politics of teaching and teacher development: With implications for educational leadership. International Journal of Leadership in Education, 1(4), 315-336. https://doi.org10.1080/1360312980010401

Hülsheger, U.R., \& Schewe, A.F. (2011). On the costs and benefits of emotional labour: A metaanalysis of decades of research. Journal of Occupational Psychology, 16(3), 361-389. https://doi.org/10.1037/a0022876

Hymel, S., Low, A., Starosta, L., Gill, R., \& Schonert-Reichl, K.A. (2017). Promoting mental well-being through social-emotional learning in schools: Examples from British Columbia. Canadian Journal of Community Mental Health, 36(4), 97-107. https://doi.org/10.7870/ cjcmh-2017-029 
Immordino-Yang, M.H., \& Damasio, A.R. (2007). We feel, therefore we learn: The relevance of affective and social neuroscience to education. Mind, Brain, and Education, 1(1), 3-10.

Immordino-Yang, M.H., Darling-Hammond, L., \& Krone, C. (2018). The brain basis for integrated social, emotional, and academic development: How emotions and social relationships drive learning. National Commission on Social, Emotional, and Academic Development. https://bit.ly/36bN94d

Isenbarger, L., \& Zembylas, M. (2006). The emotional labour of caring in teaching. Teaching and Teacher Education, 22, 120-134. https://doi.org/10.1016/j.tate.2005.07.002

Jennings, P.A., Frank, J.L., Snowberg, K.E., Coccia, M.A., Greenberg, M.T. (2013). Improving classroom learning environments by cultivating awareness and resilience in education (CARE): Results of a randomized controlled trial. School Psychology Quarterly, 28(4), 374390. https://doi.org/10.1037/spq0000035

Jennings, P.A., \& Greenberg, M.T. (2009). The prosocial classroom: Teacher social and emotional competence in relation to student and classroom outcomes. Review of Educational Research, 79(1), 491-525. https://doi.org/10.3102/00345654308325693

Jones, S.M., Bouffard, S.M., Weissbourd, R. (2013). Educators' social and emotional skills vital to learning. Phi Delta Kappan, 94(8), 62-65. https://doi.org/10.1177/003172171309400815

Karsenti, T., \& Collin, S. (2013). Why are new teachers leaving the profession? Results of Canada-wide survey. Education, 3, 141-149. https://doi.org/10.5923/j.edu.20130303.01

Kyriacou, C. (2001). Teacher stress: Direction for future research. Educational Review, 53(1), 27-35. https://doi.org/10.1080/00131910120033628

Langer Research Associates. (2019). Frustration in the schools: Teachers speak out on pay, funding, and feeling valued. The $51^{\text {st }}$ Annual PDK Poll of the Public's Attitudes Toward the Public Schools. PDK International. https://pdkpoll.org/assets/downloads/2019pdkpoll51.pdf

Lee, Y.H. (2019). Emotional labor, teacher burnout, and turnover intention in high-school physical education teaching. European Physical Education Review, 25(1), 236-253. https://doi.org/10.1177/1356336X17719559

Maslach, C. (1999). Progress in understanding teacher burnout. In R. Vandenberghe \& A.M. Huberman (Eds.), Understanding and preventing teacher burnout: A sourcebook of international research and practice (pp. 211-222). Cambridge University Press. https://doi.org/10.1017/CBO9780511527784.014

Maslach, C., Schaufeli, W.B., \& Leiter, M.P. (2001). Job burnout. Annual Review of Psychology, 52(1), 397-422.

McDonald, M. (2019, January). Teacher supply goes from glut to scarcity in a few short years. University Affairs. https://bit.ly/2YnWVgR

Moon, B. (2007). Research analysis: Attracting, developing and retaining effective teachers: A global overview of current policies and practices. Research Group on International Development in Teacher Education. UNESCO. https://bit.ly/2Lrklge

National Center for Education Statistics. (2019). Table 303.70. Total undergraduate fall enrollment in degree-granting post-secondary institutions, by attendance status, sex of students, and control and level of institutions: Selected years, 1970 through 2020. National Center for Education Statistics, U.S. Department of Education. https://nces.ed.gov/ programs/digest/d18/tables/dt18_303.70.asp

Nichols, S.L., Schutz, P.A., Rodgers, K., \& Bilica, K. (2017). Early career teachers' emotion and emerging teacher identities. Teachers and Teaching, 23(4), 406-421. https://doi.org/10.1080/13540602.2016.1211099 
Noddings, N. (1992). The challenge to care in schools: An alternative approach to education. Teacher College Press.

Noddings, N. (2012). The caring relation in teaching. Oxford Review of Education, 38(6), 771781. https://doi.org/10.1080/03054985.2012.745047

Osmond-Johnson, O. (2018). Discourse of teacher professionalism: "From within" and "from without" or two sides of the same coin? Canadian Journal of Educational Administration and Policy, 185, 61-72.

Pajares, M.F. (1992). Teachers' beliefs and educational research: Cleaning up a messy construct. Review of Educational Research, 62(3), 307-332. https://doi.org/10.3102/00346543062003307

Partelow, L. (2019). What to make of declining enrollment in teacher preparation programs. Center for American Progress. https://ampr.gs/2YnkmH6

Philipp, A., \& Schüpbach, H. (2010). Longitudinal effects of emotional labour on emotional exhaustion and dedication of teachers. Journal of Occupational Health Psychology, 15(4), 494-504. https://doi.org/10.1037/a0021046

Rushoway, K. (2020, September 24). Teacher shortage prompts call for retirees to return to Ontario classrooms. The Toronto Star. https://www.thestar.com/politics/provincial/ 2020/09/24/teacher-shortage-prompts-call-for-retirees-to-return-to-ontario-classrooms.html

Schonert-Reichl, K.A. (2017). Social and emotional learning and teachers. Future of Children, 27(1), 137-155. www.jstor.org/stable/44219025

Schonert-Reichl, K.A., Hanson-Peterson, J.L., \& Hymel, S. (2015). SEL and preservice teacher education. In J.A. Durlak, C.E. Domitrovich, R.P. Weissberg, \& T.P. Gullotta (Eds.), Handbook of social and emotional learning: Research and practice (pp. 406-421). Guilford Press.

Schonert-Reichl, K.A., Kitil, M.J., \& Hanson-Peterson, J. (2017). To reach the students, teach the teachers: A national scan of teacher preparation and social and emotional learning. A report prepared for the Collaborative for Academic, Social, and Emotional Learning (CASEL). University of British Columbia.

Shulman, L. S. (2004). The wisdom of practice: Essays on teaching, learning, and learning to teach. Jossey-Bass, Inc.

Schutz, P.A. (2014). Inquiry on teachers' emotion. Educational Psychologist, 49(1), 1-12. https://doi.org/10.1080/00461520.2013.864955

Schutz, P.A., Aultman, L.P., \& Williams-Johnson, M.R. (2009). Educational psychology perspective on teachers' emotions. In P.A. Schutz \& M. Zembylas (Eds.), Advances in teacher emotion research: The impact on teachers' lives (pp. 195-212). Springer

Science+Business Media. https://doi.org/10.1007/978-1-4419-0564-2_10

Schutz, P.A., Cross, D.I., Hong, J.Y., \& Osbon, J.N. (2007). Teacher identities, beliefs, and goals related to emotions in the classroom. In P.A. Schutz \& R. Pekrun (Eds.), Emotion in education (pp. 223-241). Elsevier.

Schutz, P.A., Hong, J.Y., Cross, D.I., \& Osbon, J.N. (2006). Reflections on investigating emotion in educational activity settings. Educational Psychology Review, 18, 343-360. https://doi.org/10.1007/s10648-006-9030-3

Schutz, P.A., \& Zembylas, M. (Eds.). (2009). Advances in teacher emotion research: The impact on teachers' lives. Springer Science+Business Media.

Sutcher, L., Darling-Hammond, L., \& Carver-Thomas, D. (2016). A coming crisis in teaching? Teacher supply, demand, and shortages in the U.S. Learning Policy Institute. https://learningpolicyinstitute.org/product/coming-crisis-teaching 
Sweeney, B. (2011, October). Education labour relations in Ontario: A report on the IRC's major research initiative. Queen's University IRC. https://irc.queensu.ca/articles/educationlabour-relations-ontario\#vii

The Association of Universities and Colleges of Canada (AUCC). (2011). Trends in higher education: Volume 1- Enrollment. AUCC. https://bit.ly/389KDgL

Uguen-Csenge, E. (2019, November 21). B.C. Teachers' Federation calls out province's teacher shortage in new ad. CBC/Radio Canada. https://www.cbc.ca/news/canada/britishcolumbia/bc-teachers-federation-ad-shortage-1.5368713

UNESCO Institute of Statistics. (2016). The world needs almost 69 million new teachers to reach the 2030 education goals. Document code: UIS/FS/2016/39. UNESCO. https://unesdoc.unesco.org/ark:/48223/pf0000246124

Walker, T. (2019, April). Teacher shortage is 'Real and growing, and worse than we thought'. NEA Today. http://neatoday.org/2019/04/03/how-bad-is-the-teacher-shortage/

Zembylas, M. (2005). Beyond teacher cognition and teacher beliefs: The value of the ethnography of emotions in teaching. International Journal of Qualitative Studies in Education, 18(4), 465-487. https://doi.org/10.1080/09518390500137642

Zembylas, M., \& Schutz, P.A. (2009). Research on teachers' emotions in education: Findings, practical implications and future agenda. In P.A. Schutz \& M. Zemblylas (Eds.), Advances in teacher emotion research (pp. 367-377). Springer Science+Business Media.

Zhu, G. (2017). Chinese student teachers' perspectives on becoming a teacher in the practicum: Emotional and ethical dimensions of identity shaping. Journal of Education for Teaching, 43(4), 1-5. https://doi.org/10.1080/02607476.2017.1341162

JT 